\title{
Evaluating the Performance of Small Scale Maize Producers in Nigeria: An Integrated Distance Function Approach
}

\author{
Goodness C. Aye ${ }^{\mathrm{a} *}$ and Eric D. Mungatana ${ }^{\mathrm{a}}$
}

${ }^{\mathrm{a}}$ Department of Agricultural Economics, Extension and Rural Development, University of Pretoria, 0002, Pretoria, South Africa

*Corresponding author: aye_goody@yahoo.co.uk

\begin{abstract}
The study evaluates the performance of small scale maize producers in Nigeria using stochastic input distance function (SIDF) and variable returns to scale data envelopment analysis (VRS DEA). Further, it examines the determinants of technical efficiency using the double-bounded Tobit regression model. Results show that maize farmers are operating below the frontier. Technical efficiency estimates from SIDF and VRS DEA models are $86.7 \%$ and $85.5 \%$ respectively. The efficiency estimates obtained from the two models are positively and significantly correlated. Given the high correlation between the two models in our analysis, and for individual variance and bias reduction, the efficiency scores from these models for each farmer are further combined into a single index using the principal component analysis (PCA) approach. Technical efficiency from the integrated model is $86.2 \%$. Our findings show that maize production could still be raised by improving farm efficiency. Age, education, household size, membership of a farmer group, access to credit and market were found to be statistically significant in explaining technical efficiency thus emphasizing the need for policy intervention in improving farm efficiency.
\end{abstract}




\section{Introduction}

Despite the oil revenue, majority of Nigerians live below the poverty line. About $64.4 \%$ of the population lives below the $\$ 1.25$ a day poverty line (UNDP, 2009). This poverty situation is worse in the rural areas where over $70 \%$ of the people reside and earn their living through agriculture. Therefore, the persistence of hunger and poverty in Nigeria must be to a large extent, the failure of the agricultural sector to fully impact positively on the people. Agricultural productivity in Nigeria has been very low.

Maize is one of Nigeria's important staples which is highly demanded for food, feed and commercial purposes. However, its productivity has been low with an average of 1.5 tonnes/ha. Theoretically, productivity increase can be achieved through land expansion, efficiency improvement and use of improved technologies. However, population growth and the consequent pressure on land resources coupled with frequent crop failures due to weather, pests, and diseases have led to greater land use intensification. Therefore, expansion of land is obviously not a likely option in Nigeria's case. The most probable options then are technological innovations and resource use efficiency. Most often, low agricultural productivity has been attributed mainly to farmers' inefficiency. In microeconomic theory, the primal production frontier, describes the maximum output that may be obtained from given inputs. A firm that operates at the production frontier has a technical efficiency of $100 \%$. Any deviation from the maximal output is typically considered technical inefficiency.

Two broad approaches are usually followed in efficiency analysis in the literatures; parametric and non-parametric approaches with each having its strengths and weaknesses. The parametric approach requires a specification of the underlying technology and or assumption about the distribution of the inefficiency term. The 
non-parametric approach neither requires a specific functional form nor an assumption about the inefficiency term. A huge number of studies have used either of these approaches (see for example Ito, 2002; Haji, 2006; Madhoo, 2007; Mitra and Sato, 2007; Okoye et al., 2007; Purohit, 2008; Solis et al., 2009). Minimizing error in the calculation of efficiency scores is very important and necessary for effective policy making. Most studies have attempted to achieve this goal by comparing various methods of measuring efficiency and subsequently the correlation between these models has been calculated (Coelli and Perelman, 1999; Sharma et al., 1997; 1999; Wadud and White, 2000; Wadud, 2003; Alene and Manfred, 2005; Herrero, 2005; Alene et al., 2006; Ajibefun, 2008; Cuesta et al., 2009). Borrowing the idea from time-series forecasting literature where many authors contend that the average of the predictions from a number of models will often outperform any one particular predictive model, Coelli and Perelman (1999) proposed a combination of efficiency measures from parametric and non-parametric models. Herrero (2005) averaged efficiency scores from alternative approaches. Alene et al. (2006) also combined efficiency scores from two models using geometric mean (GM). The GM approach assumes equal weight for each of the models. Assumption of equal weights ignores the relative importance of each indicator in the final index.

In this study, our objectives are first to evaluate the performance of maize farmers in Nigeria by estimating their efficiency levels. This is achieved using a parametric model, specifically, the stochastic input distance function (SIDF) and a non-parametric model, variable returns to scale data envelopment analysis (VRS DEA). The SIDF is preferred to the conventional stochastic frontier production function (SFPF) because the later has been critiqued for potential endogeniety problem as input factors in a production function might be jointly determined with the 
output produced. In other words, a production function is estimated when one is clearly assuming that the input quantities are decision variables thus leaving the approach to criticism that simultaneous equation bias may afflict the production frontier, and efficiency estimates may be biased (Coelli et al., 2003; Alene and Hassan, 2005; Sanford, 2010; Shee and Stefanou, 2011). The stochastic distance function avoids the endogeniety problem (Coelli et al., 2003; Berg, 2010). Admittedly, the distance function does not completely avoid endogeniety as pointed out by Kumbhakar (2011) especially when outputs are not exogenously determined as in some cases (e.g. manufacturing firms and agricultural farms except when there are explicit quotas on outputs), however, the problem is less obvious for distance functions than for production functions because input ratios (rather than inputs) are used as regressors in the former (Kumbhakar, 2011).

Secondly, we combine efficiency scores from the two models into a single efficiency index using the principal component analysis (PCA). The combination is justified based on Palm and Zellner (1992) and similar previous efficiency studies listed above. In a paper discussing methods of combining time-series forecasts, Palm and Zellner (1992 observe that "In many situations a simple average of forecasts will achieve a substantial reduction in variance and bias through averaging out individual bias". The PCA approach is preferred to the GM approach for building the integrated model because the weight of each indicator is considered when computing the final index. Moreover, the PCA approach is considered appropriate for this study as the efficiency scores from the two frontier models are highly correlated. Although, the PCA approach is not a new analytical tool in agriculture, but its application to farm efficiency analysis is unique to this study. Third, we examine the determinants of 
efficiency using a double-bounded (two-limit) Tobit model since efficiency scores are bounded between zero and one.

\section{Data}

A multistage stratified random sampling procedure was employed in selecting the respondents for this study. A total of 240 farmers were interviewed from four local government areas of Benue State, Nigeria. Data on output and input quantities were collected. The description of the variables used in estimating the frontier models is presented in Table 1 . The output variable, PROD is the quantity of maize produced by a farm household during 2008/2009 farming

Table 1: Summary statistics of variables in the frontier functions

\begin{tabular}{lllll}
\hline Variables & Mean & Std. deviation & Minimum & Maximum \\
\hline$\underline{\text { Quantities }}$ & & & & \\
PROD (kg) & 1320.38 & 656.308 & 300.000 & 3780.000 \\
LAND (ha) & 1.208 & 0.490 & 0.400 & 2.520 \\
LABOUR (man-days) & 111.195 & 101.891 & 23.000 & 720.000 \\
FERT (kg) & 115.185 & 69.207 & 0.000 & 360.000 \\
OTHER (index) & 56.343 & 49.035 & 1.865 & 310.020 \\
\hline
\end{tabular}

season and is measured in kilograms. LAND is measured as the area of land in hectares cultivated with maize. LABOUR is measured as the amount of both family and hired labour in man-days used by a farm household. FERT is the amount of inorganic fertilizer in kilograms used by a farm household. OTHER is the Fisher quantity index of seed, herbicides and pesticides used by a farm household. 
For examining determinants of efficiency, data was collected on farmers' socioeconomic characteristics and other policy and or institutional variables. The mean and description of these variables are presented in Table 2.

Table 2: Description and Mean of variables used in theTobit regression

\begin{tabular}{|c|c|c|}
\hline Variable name & Mean & Description \\
\hline Gender & 0.888 & $1=$ the household head is a male; 0 otherwise \\
\hline Age & 47.167 & Age of the household head in years \\
\hline Education & 8.433 & $\begin{array}{l}\text { Number of years of formal education completed } \\
\text { by the household head }\end{array}$ \\
\hline Household size & 11.742 & Number of persons in the household \\
\hline Land & 1.208 & Area of land in hectares cultivated with maize \\
\hline Off farm work & 0.675 & 1 = engagement in off-farm work; 0 otherwise \\
\hline $\begin{array}{l}\text { Membership of } \\
\text { Farmer group }\end{array}$ & 0.454 & $\begin{array}{l}1=\text { the household head is a member of any } \\
\text { farmer organization; } 0 \text { otherwise }\end{array}$ \\
\hline Extension & 2.546 & Number of extension visits during the cropping period \\
\hline Credit & 0.138 & $1=$ if farmer had access to credit; 0 otherwise \\
\hline Market & 6.278 & Distance to the nearest market in $\mathrm{km}$ \\
\hline
\end{tabular}

\section{Econometric Methodology}

In this section, the two distance function frontier models used in estimating farm efficiency levels are described. The integrated model and the Tobit model are also specified.

\subsection{The parametric stochastic input distance function}

The Cobb-Douglas (CD) parametric stochastic input distance function is assumed for this study. The specification is admittedly restrictive in terms of the maintained properties of the underlying production technology. However, a likelihood ratio test was conducted to test the inappropriateness of the $\mathrm{CD}$ form. The test 
revealed that the $\mathrm{CD}$ input distance function is indeed an adequate representation of the data for maize farmers in Benue State given the specification of the more flexible Translog (TL) form. For the case of single output, $\mathrm{K}$ inputs, $\mathrm{N}$ farms, the empirical model is specified as:

$$
\ln D_{i}=\delta+\alpha \ln Y_{i}+\sum_{j=1}^{4} \beta_{j} \ln X_{j i}, \quad i=1, \ldots 240,
$$

where $Y_{i}$ is the observed maize output for the $i$ th farmer and $X_{j i}=$ is the $j$ th input quantity for the $i$ th farmer, namely land, labour, inorganic fertilizer and an index of other inputs such as seed, pesticide and herbicides. In represents a natural logarithm, and $\delta, \alpha$ and $\beta_{j}$ are unknown parameters to be estimated.

The value of the distance function is not observed so that imposition of a functional form does not permit its direct estimation. A convenient way of handling this problem was suggested by Lovell et al. (1994) who exploit the property of linear homogeneity of the input distance function. Imposing the restriction for homogeneity of degree +1 in inputs upon equation (1) implies ${ }^{1}$,

$$
\sum_{j=1}^{4} \beta_{j}=1
$$

Thus, equation (1) is transformed to:

$$
-\ln X_{k i}=\delta+\alpha \ln Y_{i}+\sum_{j=1}^{4-1} \beta_{j} \ln \left(X_{j i} / X_{k i}\right)-\ln D_{i},
$$

The unobservable distance term " $-\ln \mathrm{D}_{\mathrm{i}}$ ” represents a random term and can be interpreted as the traditional stochastic frontier analysis composed disturbance term, $\varepsilon_{i}$. Thus equation (3) can be rewritten as:

\footnotetext{
${ }^{1}$ It should be noted that imposition of linear homogeneity in the case of distance function does not connote constant returns to scale as is the case with production function. For SIDF, returns to scale is computed as the negative of the inverse of the output coefficient (Estache et al., 2004; Coelli et al., 2005).
} 


$$
-\ln X_{k i}=\delta+\alpha \ln Y_{i}+\sum_{j=1}^{4-1} \beta_{j} \ln \left(X_{j i} / X_{k i}\right)+v_{i}-u_{i}
$$

The statistical noise $\left(v_{i}\right)$ is assumed to be iid $N\left(0, \sigma_{v}{ }^{2}\right)$ and independent of $u_{i}$. For this study, $u_{i}$ is assumed to be independently distributed with a half-normal distribution $\left|N\left(0, \sigma_{v}{ }^{2}\right)\right|$ given that a preliminary test rejected the alternative of truncated normal distribution at $5 \%$ level of significance.

The input-orientated technical efficiency scores are predicted using the conditional expectation predictor:

$$
\left.T \hat{E}_{i}=E\left[\exp \left(-u_{i}\right) \mid \varepsilon_{i}\right)\right]
$$

The technical efficiency measure takes a value between zero and one, with a value of one, indicating full efficiency.

\subsection{The non-parametric input distance function}

The study considers variable returns to scale DEA model. This is selected to maintain consistency with the SIDF which is also a variable returns to scale model. The VRS DEA input-oriented model is used to obtain the technical efficiency scores. For $\mathrm{N}$ farms which produce maize using $\mathrm{K}$ inputs (land, labour, fertilizer and other) and for the $i$ th farm who produces $y_{i}$ units of maize by applying $x_{j i}$ units of kth input, the $\mathrm{KxN}$ input matrix, $X$, and the $1 \mathrm{xN}$ output matrix, $Y$, represent the data for all $\mathrm{N}$ farms in the sample. The input-oriented VRS DEA model is specified as:

$$
\begin{aligned}
& \min _{\theta, \lambda} \theta, \\
& \text { st } \quad-y_{i}+Y \lambda \geq 0, \\
& \theta x_{j i}-X \lambda \geq 0, \\
& N 1^{\prime} \times \lambda=1
\end{aligned}
$$


where $\theta$ is the input technical efficiency measure having a value $0 \leq \theta \leq 1$. The resultant efficiency measure depicts the distance of each farm unit from the frontier. If the score is equal to one, it implies that the farmer is on the frontier. The vector $\lambda$ is an Nx1 vector of weights which defines the linear combination of the peers of the $i$ th farmer. $X \lambda$ and $Y \lambda$ are efficient projections on the frontier. $N 1^{\prime}$ is an $\mathrm{Nx} 1$ vector of ones and $N 1^{\prime} \times \lambda=1$ is the convexity constraint which makes the model a variable returns to scale model and it ensures that an inefficient farm is only benchmarked against farms of similar size. The linear programming problem is solved $\mathrm{N}$ times, providing a value for each farmer in the sample.

The DEA problem in equation (6) has an intuitive interpretation. The problem takes the $i$ th farm and then seeks to radially contract the input vector, $x_{i}$, as much as possible, while remaining within the feasible input set. The radial contraction of the input vector, $x_{i}$, produces a projected point, $(X \lambda, Y \lambda)$, on the surface of the production technology. This projected point is a linear combination of these observed data points. The constraints in equation (6) ensure that this projected point cannot lie outside the feasible set.

\subsection{The integrated model}

The principal component analysis (PCA) is used for integrating the efficiency scores from the two models described above into a single index. It is a widely used non-parametric statistical tool. The PCA technique has been applied in a number of studies both within and outside agriculture (Zhu, 1998; Azadeh and Jalal, 2001; Essa and Nieuwoudt, 2003; Jollans et al., 2004; Azadeh and Ghaderi 2005; Azadeh et al., 
2009). However, no study in agriculture has extended the PCA to obtain farm efficiency index.

The goal of PCA is to decompose a data table with correlated measurements into a new set of uncorrelated variables called principal components. Each principal component is calculated as a linear combination of the standardized values of the original variables used for the definition of the index. The weight given to each of these variables corresponds to its statistical correlation with the latent dimension that the index attempts to measure. The number of principal components to retrieve depends on the correlation of the initial variables. If they are strongly correlated with each other, one factor will be sufficient to explain most of their variance. However, if the correlation is weak, several factors will be required in order to explain a significant percentage of their variance. In this case, one will get a set of intermediate indicators, as many as there were common factors, and the final index will be calculated as their weighted sum. The importance of each factor is given by the proportion of the total variance explained. The first new variable $y 1$ accounts for the maximum variance in the sample data and so on. PCA is performed by identifying eigen structure of the covariance or singular value decomposition of the original data.

In this study, there are two efficiency indexes (one from parametric approach and the other from non-parametric approach) and 240 farm households. Suppose $X=\left(x_{1}, x_{2}\right)_{240 \times 2}$ is a $240 \times 2$ matrix composed by $x_{i j}{ }^{\prime} s$ defined as the value of the $j$ th index for the $i$ th farm household, therefore, $x_{m}=\left(x_{1 m}, \ldots x_{240 m}\right)^{T}(m=1,2)$. Again, suppose $\hat{X}=\left(\hat{x}_{1}, \hat{x}_{2}\right)_{240 \times 2}$ is the standardized matrix of $X=\left(x_{1}, x_{2}\right)_{240 \times 2}$ with $\hat{x}_{i j}{ }^{\prime} s$ defined as the value of the $j$ th standardized index for the $i$ th farm household and therefore $\hat{x}_{m}=\left(\hat{x}_{1 m}, \ldots \hat{x}_{240 m}\right)^{T}$. PCA is performed to identify new independent 
variables or principal components (defined as $Y_{j}$ for $\mathrm{j}=1,2$ ), which are, respectively, different linear combination of $\hat{x}_{1}$ and $\hat{x}_{2}$. This is achieved by identifying the eigen structure of the covariance of the original data. The principal component is defined by 240 x 2 matrix $Y=\left(y_{1}, y_{2}\right)_{240 \times 2}$ composed by $y_{i j}$ 's shown by:

$$
\begin{aligned}
& y_{1}=l_{11} \hat{x}_{1}+l_{12} \hat{x}_{2} \\
& y_{2}=l_{21} \hat{x}_{1}+l_{22} \hat{x}_{2}
\end{aligned}
$$

where $l_{m j}$ is the coefficient of $j$ th variable for the $m$ th principal component. $l_{m j}{ }^{\prime} s$ are estimated such that the following conditions are satisfied:

1. $y_{1}$ accounts for the maximum variance in the data, $y_{2}$ accounts for the maximum variance that has not been accounted for by $y_{1}$.

2. $l_{m 1}^{2}+l_{m 2}^{2}=1$,

3. $l_{m 1} l_{n 1}+l_{m 2} \cdot l_{n 2}=0$ for all $m \neq n \quad n=1,2$

The eigenvectors $\left(l_{m 1}, l_{m 2}\right)(m=1,2)$ are calculated and the components in eigenvectors are respectively the coefficients in each corresponding principal component, $Y_{i}$ :

$$
Y_{m}=\sum_{j=1}^{2} l_{m j} \hat{x}_{i j} \text { for } m=1,2 \text { and } i=1, \ldots, 240
$$

where $\hat{x}_{i j}$ are the values of the standardized indexes for the farm households.

The weights and PCA scores are estimated as follows:

$$
w_{j}=\lambda_{j} / \sum_{j=1}^{2} \lambda_{j}=\lambda_{j} / 2, \quad j=1,2
$$




$$
z_{i}=\sum_{j=1}^{2} w_{j} Y_{j}, \quad i=1, \ldots, 240
$$

where $w_{j}$ is the share of $j$ th eigenvalue in the population variance, $Y_{j}$ is the value of the $j$ th principal component and $z_{i}$ is the PCA score.

The ranking of the farm households is done on the basis of $Z_{i}$ and therefore it is important to recognize the elements of $Z_{i}$ so as to explore and analyze the impact of each indicator in determining the rank of each farm household. Since $Z_{i}$ is obtained from equation (13) and $Y_{j}$ is computed from equation (11), following Azadeh et al. (2009), it can be proved that

$$
\begin{aligned}
& Z_{i}=\sum_{j=1}^{2} w_{j} Y_{j}=\sum_{j=1}^{2} w_{j}\left(\sum_{j=1}^{2} l_{m j} \hat{x}_{i j}\right) \\
& =\sum_{j=1}^{2} \hat{x}_{i j}\left(\sum_{j=1}^{2} w_{j} l_{m j}\right)=\sum_{j=1}^{2} \hat{x}_{i j} \hat{w}_{m}
\end{aligned}
$$

where $\hat{w}_{m}=\sum_{j=1}^{2} w_{j} l_{m j}, m=1,2$

The value of $\hat{w}_{j}$ for each indicator shows the importance of that indicator in overall ranking of the farm households. That means, a high value of an indicator $\hat{w}_{j}$ has positive impact on the value of $Z_{i}$. To calculate efficiency score related to each farm household, the values of $\hat{w}_{j}{ }^{\prime} s$ are transformed such that they are bounded between zero and one. This is done so that these values demonstrate the differences in each indicators importance. To achieve this, each of the values of $\hat{w}_{j}$ is divided by the sum of the value of the indicators importance. The final efficiency score of $i$ th farm household is calculated as follows: 


$$
\varphi_{i}=\sum_{j=1}^{2} x_{i j} \tilde{w}_{j}, \quad i=1, \ldots, 240 ; j=1,2
$$

where $x_{i j}$ is the efficiency score generated by the $j$ th model for the $i$ th farm household and $\tilde{w}_{j}$ is the value of $\hat{w}_{j}$ that has been placed in $[0,1] . \varphi_{i}$ is the weighted sum of the efficiency scores generated by the SIDF and VRS DEA models.

\subsection{The Tobit Model}

We examine the determinants of efficiency using a double-bounded (two-limit) Tobit model since efficiency scores are bounded between zero and one. The model is specified as:

$$
\left.E F F_{i}^{*}=\beta_{0}+\sum_{k=1}^{10} \beta_{k} X_{i}+u_{i} \text { if } L_{i}<\beta_{0}+\sum_{k=1}^{10} \beta_{k} X_{i}+u_{i}<U_{i}\right\}
$$

where $E F F_{i}^{*}$ is a latent variable representing the efficiency measure for each farm household, $X_{i}$ is a $k x 1$ vector of explanatory variables for the $i$ th farm, $\beta_{k}$ is a $k x 1$ vectors of unknown parameters to be estimated, $u_{i}$ are residuals that are independently and normally distributed, with mean zero and a constant variance $\sigma^{2}$, and $L_{i}$ and $U_{i}$ are the distribution's lower and upper censoring points, respectively. Denoting $E F F_{i}$ as the observed dependent variable, $E F F_{i}=0$ if $E F F_{i}^{*} \leq 0$; $E F F_{i}=E F_{i}^{*}$ if $0<E F F_{i}^{*}<1$; and $E F F_{i}=1$ if $E F F_{i}^{*} \geq 1$.

\section{Results and discussions}

\subsection{Estimates of the parametric stochastic input distance function}

The maximum likelihood (ML) and the ordinary least square (OLS) estimates of the Cobb-Douglas SIDF are presented in Table 3. In order to qualify as a wellbehaved model, SIDF needs to be non-decreasing in inputs and decreasing in outputs 
(Färe et al., 1994). Result shows that all variables are significant at $1 \%$ and have expected signs and therefore satisfies the required conditions for monotonicity. For the parametric stochastic input distance function, the return to scale is computed as the inverse of the negative of the output coefficient (Estache et al., 2004; Coelli et al., 2005). The estimated coefficient of output is less than one in absolute terms indicating increasing returns to scale (i.e., $-1 /-0.740=1.351$ ).

The estimate of the variance parameter, $\gamma$, is 0.83 and is significant at $1 \%$ implying that $83 \%$ of the total variation in output is due to inefficiency. This result is confirmed by conducting a likelihood ratio test which tests the hypothesis of OLS model versus input distance frontier model. LR test statistic is 13.23 and this is significant when compared with the mixed chi-square value of 5.412 at one degree of freedom. Therefore, the adequacy of the OLS model in representing the data is rejected.

Table 3: The OLS and maximum likelihood estimates of the SIDF

\begin{tabular}{|c|c|c|c|c|}
\hline Variable & Mean & Parameter & OLS estimates & ML estimates \\
\hline INTERCEPT & & $\delta$ & $\begin{array}{l}3.718 * * * \\
(0.200)\end{array}$ & $\begin{array}{l}3.883 * * * \\
(0.216)\end{array}$ \\
\hline PROD & 1320.38 & $\alpha$ & $\begin{array}{l}-0.729 * * * \\
(0.021)\end{array}$ & $\begin{array}{l}-0.740^{* * * *} \\
(0.021)\end{array}$ \\
\hline LAND & 1.208 & $\beta_{1}$ & $\begin{array}{l}0.679 * * * \\
(0.022)\end{array}$ & $\begin{array}{l}0.667 * * * \\
(0.024)\end{array}$ \\
\hline $\mathrm{LAB}$ & 111.195 & $\beta_{2}$ & $\begin{array}{l}0.219 * * * \\
(0.021)\end{array}$ & $\begin{array}{l}0.233 * * * \\
(0.023)\end{array}$ \\
\hline FERT & 115.185 & $\beta_{3}$ & $0.036 * * *$ & $\begin{array}{l}0.038 * * * \\
(0.003)\end{array}$ \\
\hline OTHER & 56.343 & $\beta_{4}$ & 0.067 & $0.061^{\mathrm{a}}$ \\
\hline SIGMA-SQUARED & & $\sigma^{2}=\sigma_{u}^{2}+\sigma_{v}^{2}$ & & $\begin{array}{l}0.043 * * * \\
(0.006)\end{array}$ \\
\hline GAMMA & & $\gamma=\sigma_{u}^{2} / \sigma^{2}$ & & $\begin{array}{l}0.825 * * * \\
(0.060)\end{array}$ \\
\hline LLF & & & 125.479 & 132.274 \\
\hline
\end{tabular}
of $\beta_{4}$ is computed by the homogeneity condition 


\subsection{Comparison of efficiency scores from the alternative approaches}

The descriptive statistics of efficiency scores from the two models are presented in Table 4. The mean technical efficiency score from the SIDF model is 86.7. This implies that farmers are operating $13.4 \%$ below the frontier. Therefore, based on the SIDF result, farmers can still improve their production of maize by $13.4 \%$ given the available resources. The mean technical efficiency from the VRS DEA is 85.5 . This implies that farmers are operating $14.5 \%$ below the frontier. Therefore, based on the VRS DEA result, farmers can still improve their production of maize by $14.5 \%$ given the available resources. The efficiency estimates from the non-parametric model are slightly lower than that of the parametric model. This is because the non-parametric approach attributes all deviations from the frontier to inefficiency. Further, the efficiency estimates from the parametric distance function is less variable than that of the non-parametric approach.

Table 4: Efficiency estimates from alternative models

\begin{tabular}{lcc}
\hline Efficiency index (\%) & SIDF & VRS DEA \\
\hline Mean & 86.7 & 85.5 \\
Min & 64.3 & 51.5 \\
Max & 97.1 & 100.0 \\
SD & 7.6 & 12.9 \\
CV & 8.8 & 15.1 \\
\hline $\begin{array}{l}\text { CV = coefficient of variation; Min = minimum; Max = maximum; SD = standard } \\
\text { deviation }\end{array}$
\end{tabular}

To assess the overall consistency of the two models in ranking individual farms in terms of efficiency, the coefficient of Spearman rank-order correlation was calculated. Results are presented in Table 5. The Spearman's rank correlation 
coefficients for technical efficiency from the two models are positive and highly significant suggesting that the different farm households rank similarly when they are ordered according to either their parametric or nonparametric efficiency scores. Herrero (2005) and Cuesta et al. (2009) obtained similar high correlation between technical efficiency estimates from parametric stochastic and non-parametric distance functions. The consistency of results from these alternative approaches provides a justification for an integrated approach.

Table 5: Spearman's rank correlations among efficiency scores

\begin{tabular}{lll}
\hline & SIDF & VRS DEA \\
\hline SIDF & 1.000 & $0.705^{* * *}$ \\
& \\
VRS DEA & 1.000 \\
\hline$* * *$ significant at $1 \%$ level &
\end{tabular}

\subsection{Efficiency scores and distribution from the integrated model}

The results of efficiency distributions and some descriptive statistics from the PCA model are presented in Table 6. The mean technical efficiency index is 86.2. This implies that farmers are operating $13.8 \%$ below the frontier. Therefore, based on the integrated model result, farmers can still improve their production of maize by $13.8 \%$ given the available resources. On the other hand, if the average farm household in the sample was to achieve the technical efficiency level of its most efficient counterpart, then the average farm household could realize a $14.87 \%$ cost savings (i.e., 1-[84.2/98.9]). A similar calculation for the most technically inefficiency farm household reveals a cost saving of $47.8 \%$ (i.e., 1- [56.6/98.9]). 
Table 6: Efficiency estimates from the integrated model

\begin{tabular}{lll}
\hline Efficiency index (\%) & Number & Percent \\
\hline$\leq 50$ & 0 & 0 \\
$51-60$ & 3 & 1.25 \\
$61-70$ & 17 & 7.08 \\
$71-80$ & 30 & 12.50 \\
$81-90$ & 108 & 45.00 \\
$91-100$ & 82 & 34.17 \\
Mean & 86.20 & \\
Min & 59.71 & \\
Max & 98.31 & \\
SD & 9.11 \\
CV & 10.57 \\
\hline CV = coefficient of variation; Min = minimum; Max = maximum; SD = standard \\
deviation
\end{tabular}

\subsection{Determinants of technical efficiency}

The Tobit estimates of the determinants of technical efficiency from the integrated model are reported in Table 7. The significance of the likelihood ratio (LR) test in each model implies the joint significance of all variables included in the model. The effect of age on efficiency could be ambiguous, depending on whether older farmers are more experienced or more likely to stick to farming traditions and less likely to adopt new technologies. Age has a positive sign and significant impact on technical efficiency. Thus, the variable indexes experience and serve as a proxy for 
human capital showing that farmers with greater farming experience will have better management skills and thus higher efficiency than younger farmers. The positive and significant impact of age is consistent with the findings of Khai et al. (2008). The second human capital variable, education has positive and significant impact on technical efficiency implying that the more educated a farmer is the more he is able to produce at or near the frontier. The result is consistent with those of Wadud and White (2000) and Oyewo and Fabiyi (2008).

Table 7: Determinants of technical efficiency

\begin{tabular}{lll}
\hline Variable & Coefficient & Standard Error \\
\hline Gender & -0.014 & 0.013 \\
Age & $0.003^{* * *}$ & 0.000 \\
Education & $0.003^{* * *}$ & 0.001 \\
Household size & $0.001^{* *}$ & 0.001 \\
Land & -0.004 & 0.009 \\
Off farm work & -0.014 & 0.009 \\
Membership of Farmer group & $0.053^{* * *}$ & 0.015 \\
Extension & -0.002 & 0.002 \\
Credit & $0.031^{* *}$ & 0.012 \\
Market & $-0.001 *$ & 0.001 \\
Intercept & $0.685^{* * *}$ & 0.026 \\
LLF & 323.564 & \\
LR Test & $190.74 * * *$ & \\
\hline
\end{tabular}


Household size was found to be positively and significantly related to technical efficiency. This finding indicates the importance of abundant labour supply especially for labour intensive farming. Membership in a farmer group indexes social capital and affords the farmers opportunity of sharing information on modern maize practices by interacting with others as well as provides farmers with bargaining power in the input, output and credit markets. As expected, this variable was found to be $\mathrm{c}$ positive and significant. The positive and significant impact is consistent with the findings of Ogunyinka and Ajibefun (2004). Credit has a positive and significant effect on technical efficiency. This is as expected since the availability of credit loses the production constraints thus facilitating timely purchase of inputs and therefore increases productivity via efficiency. The result is consistent with the findings of Muhammad (2009) but contrast with that of Haji (2006) who rather found a negative though not significant impact of credit access to technical efficiency.

Market was included to capture farmers' access to market. It serves as a proxy for the development of road and market infrastructures. It is generally believed that farms located closer to the market are more efficient than the farms located farther from the market. This expectation was satisfied in this study as the market was correctly signed and had significant impact on technical efficiency.

\section{Conclusion and policy implications}

The study evaluated the performance of small scale maize producers in Nigeria using three alternative approaches, namely parametric stochastic input distance function (SIDF) and two non-parametric distance functions (VRS DEA and CRS DEA). Results show that maize farmers are operating below the frontier. Technical efficiency estimates from SIDF, VRS DEA and CRS DEA models are 
$86.7 \%, 85.5 \%$ and $80.1 \%$ respectively. The efficiency estimates obtained from the three models are positively and significantly correlated. Given the high correlation between the two models in our analysis, and for individual variance and bias reduction, the efficiency scores from these models for each farmer are further combined into a single index using the principal component analysis (PCA) approach. Technical efficiency from the integrated model is $86.2 \%$. This implies that the production of maize could be increased by $13.8 \%$ by improving farm efficiency. The result that farmers have achieved high technical efficiency supports Schultz's (Schultz, 1964) "poor but efficient"' hypothesis, which implies that opportunities for production gains through efficiency improvement are limited and hence new technologies must be introduced to enhance the productivity of such systems. Complementary policy interventions to enhance the success of any technological package may include access to credit, market, formal education among others. In general, agriculture in Nigeria needs total transformation.

\section{Acknowledgements}

The authors are very grateful to the German Academic Exchange Service (DAAD) and World Bank Margaret McNamara Memorial Fund (MMMF) for sponsoring the study. We also thank the University of Agriculture, Makurdi, Nigeria for granting the study leave in support of this research.

\section{References}

Ajibefun, I. A. 2008. An Evaluation of Parametric and Non-Parametric Methods of Technical Efficiency Measurement: Application to Small Scale Food Crop Production in Nigeria. Journal of Agriculture and Social Sciences, 4 (3): 95100.

Alene, D.A. and Hassan, R.M. 2005. The Efficiency of Traditional and Hybrid Maize Production in Eastern Ethiopia: Extended Efficiency Decomposition Approach. Journal of African Economies, 15 (1): 91-116. 
Alene, D. A. and Manfred Z. 2005. Technology Adoption and Farmer Efficiency in Multiple Crops Production in Eastern Ethiopia: A Comparison of Parametric and Non-Parametric Distance Functions. Agricultural Economics Review, 6(1), 5-19.

Alene, D.A, Manyong, V.M. and Gockowski, J. 2006. The Production Efficiency of Intercropping Annual and Perennial Crops in Southern Ethiopia: A Comparison of Distance Functions and Production Frontiers. Agricultural Systems, 91: 5170.

Azadeh, M.A. and Jalal, S. 2001. Identifying the Economic Importance of Industrial Sectors by Multivariate Analysis. Journal of the Faculty of Engineering, 35(3): 437-449.

Azadeh, A. and Ghaderi, F. 2005. A Total Productivity PCA Model for Assessment and Improvement of Electrical Manufacturing Systems. Journal of Mathematics and Statistics, 1(3): 252-256.

Azedah, A., Ghaderi, S.F. Omrani, H. and Eivazy, H. 2009. An Integrated DEACOLS-SFA Algorithm for Optimization and Policymaking of Electricity Distribution Units.Energy Policy, 37: 2605-2618.

Berg, S. V. 2010. Water Utility Benchmarking: Measurement, Methodologies, and Performance Incentives. IWA Publishing, London, Uk, pp. 153-154.

Coelli, T. and Perelman, S. 1999. Theory and Methodology: A Comparison of Parametric and Non-Parametric Distance Functions: With Application to European Railways. European Journal of Operational Research, 117: 326-339.

Coelli, T., Fleming, E. and Singh, S. 2003. An Input Distance Function Approach to the Measurement of Technical and Allocative Efficiency. Contributed Paper Presented at the 8th European Workshop on Efficiency and Productivity Analysis, Oviedo, Spain, 25-27 Sept, 2003.

Coelli T, Prasada Rao D.S, and Battese G.E. 2005. An Introduction to Efficiency and Productivity Analysis, 2nd edition. Kluwer Academic Publishers: Norwell, Dordrecht.

Cuesta, R.A., Lovell, C.A.K. and Zofío, J.L. 2009. Environmental Efficiency Measurement with Translog Distance Functions: A Parametric Approach. Ecological Economics, 68: 2232-2242.

Essa, J.A. and Nieuwoudt, W.L. 2003. Socio-economic Dimensions of Small-Scale Agriculture: A Principal Component Analysis. Development Southern Africa, 20(1): 67-73.

Estache, A., Rossi, M.A., and Ruzzier, C.A. 2004. The Case for International Coordination of Electricity Regulation: Evidence from the Measurement of Efficiency in South America. Journal of Regulatory Economics, 25 (3): 271295.

Färe, R., Grosskopf, S., and Lovell, C.A.K. 1994. Production Frontiers. Cambridge University Press, Cambridge.

Haji, J. 2006. Production Efficiency of Smallholders' Vegetable-Dominated Mixed Farming System in Eastern Ethiopia: A Non-parametric Approach, Journal of African Economies, 16(1): 1-27.

Herrero, I. 2005. Different Approaches to Efficiency Analysis: An Application to the Spanish Trawl Fleet Operating in Moroccan Water', European Journal of Operational Research, 167: 257-271.

Ito, H. 2002. Efficiency Changes at Major Container Ports in Japan: A Window Application of Data Envelopment Analysis. Review of Urban and Regional Development Studies, 14(2):131-152. 
Khai, H.V., Yabe, M., Yokogawa, H., and Sato, G. 2008. Analysis of Productive Efficiency of Soybean Production in the Mekong River Delta of Viet Nam. Journal of Faculty of Agriculture, Kyushu University, 53 (1): 271-279.

Kumbhakar, S.C. (2011) Estimation of Multiple Output Production Functions. http://www.econ.gatech.edu/files/seminars/kumbhakar.pdf

Lovell, C.A.K., Richardson, S., Travers, P and Wood, L.L. (1994). Resources and Functionings: A new view of inequality in Australia, In Eichlorn, W. (ed.), Models and Measurement of Welfare and Inequality, Berlin, Springer-Verlag.

Madhoo, Y.N. 2007. Modeling the Economic Efficiency of Irrigation Water supply in Dry and Humid Regions. Review of Urban and Regional Development Studies, 19(2): 103-122.

Mitra, A. and Sato, H. 2007. Agglomeration Economies in Japan: Technical Efficiency, Growth and Unemployment. Review of Urban and Regional Development Studies, 19(3):197-209.

Muhammad, I.J. 2009. Efficiency Analysis of Cotton-Wheat and Rice-Wheat Systems in Punjab, Pakistan. PhD thesis, University of Agriculture, Faisalabad. http://prr.hec.gov.pk/Thesis/36S.pdf

Ogunyinka, E.O. and Ajibefun, I. A. 2004. Determinants of Technical Inefficiency on Farm Production: Tobit Analysis Approach to the NDE Farmers in Ondo State, Nigeria. International Journal of Agriculture and Biology, 2, 355-358.

Okoye, B.C., Onyenweaku, C.E. and Asumugha, G.N. 2007. Allocative Efficiency of Small-Holder Cocoyam Farmers in Anambra State, Nigeria, Agricultural Journal, 4(38):70-81.

Oyewo, I. O. and Fabiyi, Y.L. 2008. Productivity of Maize Farmers' in Surulere Local Government Area of Oyo State. International Journal of Agricultural Economics and Rural Development, 1 (2): 25-34.

Palm, F.C., and Zellner, A., 1992. To Combine or Not to Combine? Issues of Combining Forecasts. Journal of Forecasting, 11,687-701.

Purohit, B.C. 2009. Efficiency of the Health Care System: A Sub-state Level Analysis for West Bengal (India). Review of Urban and Regional Development Studies 20(3):212-225.

Schultz, T.W., 1964. Transforming Traditional Agriculture. Yale University Press, New Haven, USA.

Sharma, K.R., Leung, P., and Zalleski, H.M., 1997. Productive Efficiency of the Swine Industry in Hawaii: Stochastic Frontier vs. Data Envelopment Analysis. Journal of Productivity Analysis, 8, 447-459.

Sharma, K.R., Leung, P., and Zalleski, H.M., 1999. The Technical, Allocative, and Economic Efficiencies in Swine Production in Hawaii: A Comparison of Parametric and Non-parametric Approaches. Agricultural Economics, 20: 2335 .

Shee, A. and Stefanou, S.E. 2011. Bounded Learning Efficiency and Sources of Firm Level Productivity Growth in Colombian Food Manufacturing Industry. Contributed Paper at Agricultural and Applied Economics Association 2011 Annual Meeting, July 24-26, 2011, Pittsburgh, Pennsylvania. http://ideas.repec.org/p/ags/aaea11/103898.html

Solis, D., Bravo-Ureta, B.E. and Quiroga, R.E. 2009. Technical Efficiency among Peasant Farmers Participating in Natural Resource Management Programmes in Central America', Journal of Agricultural Economics, 60(1): 202-219. 
United Nations Development Programme, 2009. Human Development Report: Overcoming Barriers to Human Mobility and Development, http://hdr.undp.org/en/media/HDR_2009_EN_Indicators.pdf

Wadud, A and White, B. 2000. Farm Household Efficiency in Bangladesh: a Comparison of Stochastic Frontier and DEA Methods. Applied Economics, 32(13): 1665-1673.

Wadud, A. 2003. Technical, Allocative, and Economic Efficiency of Farms in Bangladesh: A Stochastic Frontier and DEA Approach. The Journal of Developing Areas, 37 (1): 109-126.

Zhu, J. 1998. Data Envelopment Analysis vs. Principal Component Analysis: An Illustrative Study of Economic Performance of Chinese Cities. European Journal of Operation Research, 111: 50-61. 